\title{
Different Sources of Isolation and Some Determinants of Pathogenicity of Multidrug- Resistant Staphylococcus aureus Strains
}

\author{
Shorena Khetsuriani ${ }^{1}$, Khatuna Pochkhua ${ }^{2}$, Maia Zarnadze ${ }^{3}$ \\ ${ }^{1}$ Tbilisi State Medical University, Tbilisi, Georgia \\ ${ }^{2}$ St. Andrew the First-Called Georgian University of the Patriarchate of Georgia, \\ ${ }^{3}$ PetreShotadze Medical Academy, Tbilisi, Georiga
}

\begin{abstract}
Staphylococcus aureus expresses a variety of extracellular proteins and polysaccharides, some of which are correlated with virulence. The aims of study were to identify of multidrug-resistant S. aureus(MDRSA) strains isolated from different sites of patients, to determine their pathogenicity factors, enzymes, ability of carbohydrate fermentation. Study results show that some determinants of pathogenicity (plasma coagulase, catalase, urease, lecithinase production, hemolysis, proteolysis), also carbohydrates and mannitol fermentation in aerobic and anaerobic conditions arecharacterized high activity in MDRSA strains. The most common wasisolation of these strains from patients with oral cavity infections, a few cases - from peritoneal liquid and phlegmon.
\end{abstract}

Keywords: S. aureus, multidrug-resistance, enzymes, carbohydrate fermentation, oral cavity, peritoneal liquid, phlegmon.

\section{Introduction}

Although advances in medical research and treatments, infectious diseases are among the leading causes of death worldwide. In addition to the discovery of new pathogens, old infectious disease agents are "re-emerging". Natural genetic variations, recombinations and adaptations allow new strains of known pathogens to appear [9]. Therefore, the leading institutions research plans and priorities include developing new strategies to control diseases that are reemerging due to drug resistance also [14].

Staphylococcus aureus is among the most prevalent causes of clinical infections globally and has attention due to increasing mortality associated with multidrug resistance [12]. Due to these reasons, it named as a "superbug" [6]. $S$. aureus is the most commonly isolated human bacterial pathogen and is an important cause of skin and soft tissue infections, endovascular infections, pneumonia, septic arthritis, endocarditis, osteomielitis, foreign-body infections and sepsis [11]. S. aureus is now the leading overall causeof nosocomial infections and as more patients are treated outside the hospital setting, is an increasing concern in the community [10]. This bacteriumis a common cause of infections in patients in intensive care and in many countries often are multidrug-resistant S. aureus (MDRSA) i.e. it is resistant to most antibiotics. There were considerable variations among patients from different geographical regions [7]. Hence, the knowledge of current trend of MDRSA in hospital environment as well as in the community is necessary $[3,12]$.

One of the reasons for the success of this human pathogen is its great variability, occurring at different periods and places with diverse clonal types and antibiotic resistance patterns within regions and countries [1].
Aim of study: to identify of MDRSAstrains isolated from various sites of patients with different infections, to determine enzymes which are correlated with virulence also.

\section{Materials and Methods}

There were studied 279clinicalisolates of MDRSA. They wereidentifiedbythecorresponding methods [2,4]. S. aureus strains were provided by the Clinic "Aversi", Eliava Scientific Research Institute of Microbiology, Virology and bacteriology and V. Bochorishvili Sepsis Center (Tbilisi, Georgia).Strains were examined according to morphological (colonies), microscopical (cell), tinctorial (Gram staining) parameters.Cultivation of $S$. aureus were performed on meat-peptone agar, meat-peptone broth, 5\% blood agar, egg yolk-salt agar, milk-salt agar of Eikman; also studied cultivation ability on low $\left(15^{\circ} \mathrm{C}\right)$ and high $\left(45^{\circ} \mathrm{C}\right)$ temperatures. Biochemical properties have been analyzed on results of carotenoid pigment formation, carbohydrate fermentation in aerobic and anaerobic conditions, urease, catalase, hemolytic, coagulase, lecithinase, proteolytic activities and novobiocin susceptibility tests. The study of antibiotic resistance were performed by using of automated microbial identification system (VITEK2 Biomerieux analyzer) and disc diffusion method [4,8].

\section{Results}

As seen in table 1, the greater number of MRSA strains were isolated from oral cavity $-19.35 \pm 2.98 \%$, from the pharynx and wound infection $-14.44 \pm 2.93 \%$ from each. There were a few cases of isolation of strains from peritoneal liquid and phlegmon. In other cases number of isolated strains varied according to the site of isolation.

Frequency of MRSA strains isolated from different human sites

Volume 6 Issue 12, December 2017 www.ijsr.net 


\section{International Journal of Science and Research (IJSR)}

ISSN (Online): 2319-7064

Index Copernicus Value (2016): 79.57 | Impact Factor (2015): 6.391

\begin{tabular}{|c|c|c|}
\hline Source of Isolation & Abs. & $\%$ \\
\hline Oral cavity & 54 & $19.35 \pm 2.98$ \\
\hline Pharynx & 40 & $14.44 \pm 2.93$ \\
\hline Ear & 11 & $3.94 \pm 1.87$ \\
\hline Eye & 13 & $4.65 \pm 2.01$ \\
\hline Nose & 24 & $8.60 \pm 2.55$ \\
\hline Trachea & 11 & $3.94 \pm 1.87$ \\
\hline Skin & 17 & $6.09 \pm 2.25$ \\
\hline Tropic ulcer & 16 & $5.73 \pm 2.10$ \\
\hline Wound & 40 & $14.44 \pm 2.93$ \\
\hline Blood & 12 & $4.30 \pm 1.94$ \\
\hline Urine & 10 & $3.58 \pm 1.79$ \\
\hline Peritoneal liquid & 6 & $2.15 \pm 1.42$ \\
\hline Phlegmon & 6 & $2.15 \pm 1.42$ \\
\hline Vagina & 11 & $3.94 \pm 1.87$ \\
\hline Prostatic secret & 8 & $2.86 \pm 1.62$ \\
\hline
\end{tabular}

There were studied some biochemical characteristics of MRSA strains $(n=50)$ which are one of the pathogenicity determinants of these strains. Lecithinase active and ureasepositive were $96.0 \pm 2.77 \%$ strains.Proteolytic activity (production of $\mathrm{H}_{2} \mathrm{~S}$ ) andcarbohydratefermentation in aerobic conditions detected in $94.0 \pm 3.35 \%$ cases.Mannitol fermentation in anaerobic conditions revealed in $92.0 \pm 3.83 \%$ of strains.Plasma coagulase activity and ability of carbohydrate fermentation in anaerobic condition, hemolytic activity (hemolysis) revealed in all strains - $100 \%$.

Some Determinants of Pathogenicity of MRSA strains $(n=50)$

Table 2

\begin{tabular}{|l|c|c|}
\hline Identity Marks & Abs. & $\%$ \\
\hline Hemolysis & 50 & 100 \\
Plasma coagulase positive & 50 & 100 \\
Catalase positive & 50 & 100 \\
Urease positive & 48 & $96.0 \pm 2.77$ \\
Lecithinase activity & 48 & $96.0 \pm 2.77$ \\
Production of $\mathrm{H}_{2} \mathrm{~S}$ & 47 & $94.0 \pm 3.35$ \\
Carbohydrate fermentation & 47 & $94.0 \pm 3.35$ \\
Mannitol fermentation in anaerobic condition & 46 & $92.0 \pm 3.83$ \\
\hline
\end{tabular}

\section{Conclusion}

Most frequently MRSA strains were isolated from patientsoral cavity $-19.35 \pm 2.98 \%$ and from the pharynx and wound infections $-14.44 \pm 2.93 \%$ from each; only a few cases were of isolation of these strains from peritoneal liquid and Phlegmon. In other cases number of isolated strains varied according to the site of isolation.

Some determinants of pathogenicity (plasma coagulase, catalase, urease, lecithinase production, hemolysis, proteolysis), also carbohydrates and mannitol fermentation in aerobic and anaerobic conditions are characterized with high activity in MDRSA.

\section{References}

[1] Akindele A.A. Adewiuyi I. K. at al Antibioticogram and beta-lactamase production of Staphylococcus aureus isolates from human clinical specimens $\mathrm{n}$ a Tertiary

Health Institution in Nigeria. American - Eurasian Journal of Scientific research 2010, 5(4): 230-233,

[2] Baron EJ. Peterson L.R., Finegold SM. - Diagnostic Microbiology 9th edition Mosby 1999, p 320-345

[3] Barua S., Joshi A Sh., Swaminathan R. Prevalence of Multidrug Resistant Staphylococcus aureus and its Antimicrobial Susceptibility Pattern in a Tertiary Care Hospital in Navi Mumbai, India Int.J.Curr.Microbiol.App.Sci (2017) 6(3): 370-375

[4] Bergey's Manual of Determinative Bacteriology John G. Holt Lippincott Williams \& Wilkins, 1994 -787 pages

[5] Clinical and Laboratory Standards Institute. Performance standards for antimicrobial disk susceptibility tests. Approved standard. 9th ed.(M2-A9). Wayne, PA: Clinical and Laboratory Standards Institute; 2006.

[6] Hanberger H. et al. Increased mortality associated with methicillin-resistant Staphylococcus aureus (MRSA infection in the Intensive care Unit: results from the EPIC II study).International journal of Antimicrobial Agents, 2011 Oct; 38(4):331-5.

[7] Hamilton S. M. Amy E. Et all. In vitro Production of Panton-Valentine Leucocidin among strains of Methicillin-resistant Staphylococcus aureus Causing Diverse Infections. Clinical Infectious Diseases. 2007, Vol. 54, Issue 12 p 1550-1558

[8] Jorgensen, J. H., and J. D. Turnidge. 2007. Susceptibility test methods: dilution and disk diffusion methods, p. 1152-1172. In P. R. Murray, E. J. Baron, J. H. Jorgensen, M. L. Landry, M. A. Pfaller (ed.), Manual of clinical microbiology, 9th ed. ASM Press, Washington, D.C

[9] Kaszanyitsky EJ. Janosi S. Egyed Z, Agost G. Semjen G Antibiotic resistance of staphylococci from humans, food and different animal species according to data of the Hungarian resistance monitoring system in 2001. Acxta Vet. Hung. 2003;51 (4); 451-64

[10] Lowy F. D. Staphylococcus aureus infections. N. Engl. J. Med. 1998, 339;520-532.59

[11] Mc callumn. N., Berger-Bachi B., Senn M. -Regulation of antibiotic resistance in Staphyloccus aureus. Int. J. of Med. Microb. vol. 300, issues 2-3 Febr. 2010, p 118 129

[12] Mc Murray L. W. Kernodle D.S. Barg N.L. Characterisation of widespread strains of methicillinsusceptible Staphylococcus aureus associated with nosocomial infections J. Infect. Dis.1990,162; 759-762

[13] Rajaduraipandi, K., K.R. Mani, K. Panneerselvam, M. Mani, M. Bhaskar, P. Manikandan. 2016. Prevalence and Antimicrobial Susceptibility pattern of Methicillin Resistant Staphylococcus aureus: A Multicentre Study. Indian J. Med. Microbiol., 24(1): 34-8

[14] Sola C., Lamberghini R. et all. Heterogenousvancomicin-intermediate susceptibility in a community-associated methicillin resistant Staphylococcus aureus epidemic clone, in a case of infective endocarditis in Argentina. Ann ClinMicrobiol. Antimicrob. 2011; 10: 15. 